\title{
Climate change impact of wind energy availability in the Eastern Mediterranean using the regional climate model PRECIS
}

\author{
A. Bloom, V. Kotroni, and K. Lagouvardos \\ National Observatory of Athens, Institute of Environmental Research, Athens, Greece \\ Received: 18 April 2008 - Revised: 13 October 2008 - Accepted: 13 October 2008 - Published: 24 November 2008
}

\begin{abstract}
Global near-surface wind fields are projected to change as a result of climate change. An enhanced knowledge of the changes in wind energy availability in the twentyfirst century is essential for improving the development of wind energy production. We use the PRECIS regional model over the East Mediterranean to dynamically downscale the results of the Had3CM Atmosphere-Ocean coupled Global Circulation Model. Wind field changes during the 21st century are determined by comparing the current climate simulation (1961-1990) with the IPCC A2 emissions scenario simulation (2071-2100). The consistency of the current climate simulation of wind speeds is assessed by comparing its results to the ERA40 re-analysis data. The comparison of the wind field from ERA40 re-analysis to that from the PRECIS current climate simulation shows relatively large mean differences that could partly be attributed to the difference in the spatial resolution of the two sources of data. Wind speeds in 2071-2100 exhibit a general increase over land and a decrease over the sea, with the exception of a noticeable increase over the Aegean Sea.
\end{abstract}

\section{Introduction}

Wind speeds over Europe are projected to change during the twenty-first century as a result of enhanced greenhouse gas conditions (Rockel and Woth, 2007). Changes in wind patterns have significant implications on the potential of wind as an energy resource (e.g. Pryor et al., 2005). Therefore it is of crucial importance to quantify changes in wind energy availability in order to assist the development of wind energy production up to the end of the century.

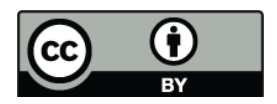

Correspondence to: V. Kotroni (kotroni@meteo.noa.gr)
Dynamic downscaling is a physically-based method of deriving finer-scale regional information from Global Circulation Models (GCM): this is accomplished by driving a regional climate model (RCM) with boundary conditions from a GCM. Räisänen et al. (2004) have conducted a dynamically downscaled RCM study over Europe in order to evaluate the effects of climate change during the end of the 21st century (2071-2100) based on the IPCC (Intergovernmental Panel on Climate Change) A2 and B2 green-house gas emission scenarios (IPCC 2001). Their study shows an increase in windiness by about $8 \%$ in northern Europe, a decrease mainly in the central Mediterranean and a modest increase over southeastern Europe following the A2 scenario. Moreover they have shown that mean and maximum wind speeds are very sensitive to the RCM boundary conditions.

Pryor et al. (2005) have conducted a more extensive study of the effects of climate change on wind speeds and wind energy production in 2071-2100 over northern Europe. The RCM used in that study was driven by boundary conditions from two different GCMs and for both the A2 and B2 emission scenarios. They found evidence for a small increase in the annual wind energy resource over northern Europe and more substantial increase in energy density during the winter season. Rockel and Woth (2007) outline the need to further examine the RCM derived evolution of wind speeds over Europe using different boundary conditions and different RCMs: these comparisons are required to test the sensitivity of the RCM to uncertainties arising from land use change, emission scenarios and gust parameterization schemes. The authors have shown that the climate models without gust parameterisations are not able to realistically reproduce high wind speeds. In the same study the analysis of an ensemble of RCM simulations indicated a possible increase in future mean daily wind speed during winter months, and a decrease during autumn in areas of Europe influenced by North-Atlantic extra-tropical cyclones. 
The present paper aims to quantify the changes in wind speed and wind energy density in the Eastern Mediterranean between the current climatic conditions and future climate projections derived from the A2 emissions scenario during 2071-2100. For the analysis, we use the regional climate model simulations performed with PRECIS model over the Eastern Mediterranean at a horizontal resolution of $\sim 25 \times 25 \mathrm{~km}$. So far, a large number of climate model simulations of future climate change have been performed over Europe and the Mediterranean using horizontal grid spacing of the order of $50 \mathrm{~km}$ and a very limited number of higher resolution climate change simulations $(12-25 \mathrm{~km}$ grid) have been completed. Gao et al. (2006) who performed and analysed high resolution regional climate model simulations (at 20-km grid spacing) have concluded that topography induces fine scale features to the signal of the meteorological parameters and therefore that fine resolution models are necessary to provide more detailed future climate information for impact assessment studies. Thus the grid spacing of the regional scale climate simulations presented in the present study is considered necessary in order to study climate change impacts in the Eastern Mediterranean which is characterised by complex topography and land-water distribution.

\section{Method}

The experiments used in this study have been performed with the regional climate modelling system PRECIS that has been developed at the Hadley Centre (UK Meteorological Office). The aim was to add fine-scale detail to the broad-scale projections provided by the GCM developed and used at the Hadley Centre and consequently to assist the generation of climate change scenarios and the decision making on adaptation strategies at regional scale. PRECIS is based on the atmospheric component of HadCM3 climate model (Gordon et al., 2000) and it is described in detail in Jones et al. (2004). It is a hydrostatic model that uses the full primitive equations and employs a regular latitude-longitude grid in the horizontal and a hybrid vertical coordinate. The model requires prescribed surface and lateral boundary conditions. Surface boundary conditions are updated every $24-\mathrm{h}$ while lateral boundary conditions are updated every $6 \mathrm{~h}$.

For the present (1961-1990) and future (2071-2100) climate simulations with PRECIS model, surface and lateral boundary conditions were provided by the HadAM3P global atmosphere-only climate model that was run at $150-\mathrm{km}$ resolution (Gordon et al., 2000; Pope et al., 2000). HadAM3P was used in its turn to downscale the results of HadCM3 Atmosphere Ocean Global Climate Model (AOGCM) and its integrations are available for the periods 1961-1990 (present climate) and 2071-2100 for the A2 and B2 scenarios of the IPCC Special Report on Emissions Scenarios (SRES30-year period).

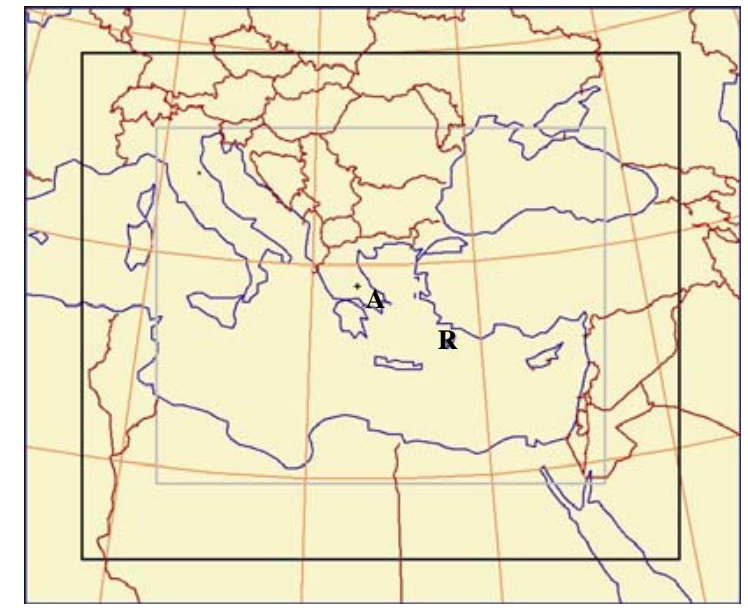

Fig. 1. Representation of PRECIS model domain of integration. A denotes the position of Athens, and $\mathrm{R}$ the position of Rhodes island.

The PRECIS RCM has been implemented over the East Mediterranean between approximately $8^{\circ} \mathrm{E}$ to $20^{\circ} \mathrm{E}$ and $25^{\circ} \mathrm{N}$ to $48^{\circ} \mathrm{N}$. Experiments were performed at a horizontal resolution of $0.22^{\circ} \times 0.22^{\circ}(\sim 25 \times 25 \mathrm{~km})$. For the model integration 19 vertical levels were set from the surface to the $0.5 \mathrm{hPa}$ level. Figure 1 shows a map of the domain of integration of PRECIS model. Validation of PRECIS simulations of the current climate is presented in Kotroni et al. (2008). More specifically, the authors have verified the 30 -year climate model simulations of the near-surface air temperature and precipitation against available surface station observations with the aim to assess the model's ability to reproduce the present-day-climate and identify eventual systematic model errors.

The ability of PRECIS model to simulate the climatic wind speed in the 30-year period between 1961 and 1990 is examined, in the frame of this work, by comparing the PRECIS output to the ERA 40 re-analysis data available at $1^{\circ} \times 1^{\circ}$ resolution during the same period provided by ECMWF. PRECIS output data were aggregated using an inverse square relation to match the overlapping ERA40 data. Wind speed and wind energy density comparisons between the two 30 year periods of 1961-1990 and 2071-2100 (A2 scenario) were made. Ten meter wind speeds are used for the comparison, thus excluding the error introduced by the potentially highly variable wind shear exponent (e.g. Farrugia, 2003). The energy density $(E)$ time series has been derived from the time series of wind speed $(U)$ using the expression: $E=(1 / 2) \rho U^{3}$, where $\rho$ is the air density. For all calculations the four-times daily (00:00, 06:00, 12:00, 18:00 UTC) 10-m wind speeds have been used. 

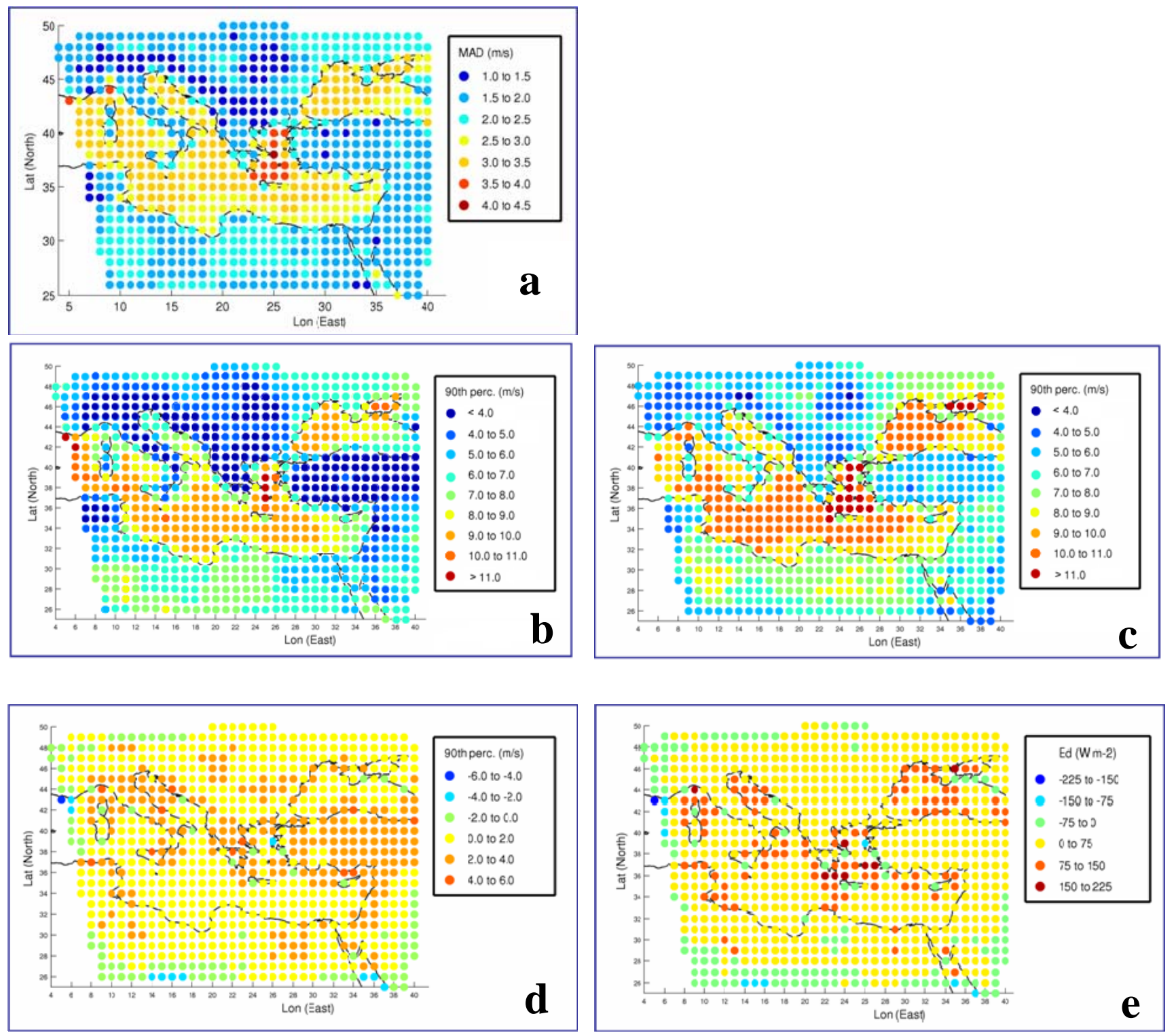

Fig. 2. Comparison between the PRECIS current climate simulation (1961-1990) and ERA40 re-analysis of 10-m wind speeds for the same period: (a) mean absolute difference, (b) ERA40 wind speed 90th percentile, (c), PRECIS wind speed 90th percentile (d) PRECIS-ERA40 wind speed 90th percentile difference, (e) PRECIS-ERA40 energy density difference.

\section{Results and discussion}

Figure 2 shows the comparisons between the aggregated $1^{\circ} \times 1^{\circ}$ resolution PRECIS control run (1961-1990) and the ERA40 re-analysis 10-m wind field: the comparative statistical measures include the PRECIS-ERA40 mean absolute difference (MAD, Fig. 2a), the ERA40 wind speed 90th percentile (Fig. 2b), the PRECIS wind speed 90th percentile (Fig. 2c), the PRECIS-ERA40 90th percentile difference (Fig. 2d) and the energy density difference (Fig. 2e). The comparison between the PRECIS simulation and the ERA40 re-analysis exhibits smaller differences over land than over the sea, with the MAD varying from 1 to $2.5 \mathrm{~ms}^{-1}$ and from
2.5 to $4.5 \mathrm{~ms}^{-1}$ respectively (Fig. 2a). The largest MAD values are observed over the Aegean Sea. These differences could be attributed to the different spatial resolution of ERA40 $\left(1^{\circ} \times 1^{\circ}\right)$ and of PRECIS model $\left(0.22^{\circ} \times 0.22^{\circ}\right)$. Although PRECIS wind data have been aggregated to a lower resolution, it should be taken into account that the higher resolution permits to better resolve the highly complex orography and land-water distribution over the area. The difference in the spatial resolution and thus in the degree of specificality of the underlying terrain induces differences in the drag and the blocking by the mountains and thus can partly explain the observed discrepancies of the $10-\mathrm{m}$ wind field. 
In literature, the major part of validation studies of regional climate model simulations against observations involve near-surface temperature, precipitation and sea-level pressure while the validation of $10-\mathrm{m}$ wind speed is limited. Krichak et al. (2007) in their study based on a three-member ensemble climate change simulation experiment compared the current climate simulations with the Climate Research Unit data available at $0.5^{\circ} \times 0.5^{\circ}$ grid spacing based on observations from land stations only in the easternmost part of the Mediterranean. In their study the authors provided a qualitative comparison of the two data sources and found that the locations of the simulated areas with wind maxima are in reasonably good agreement with the CRU data. Nevertheless at locations over the Easternmost Mediterranean such as over the Northern African Coasts, eastern Egypt and Jordan the model underestimates the wind by $\sim 2.5 \mathrm{~ms}^{-1}$ during winter while during summer at locations such as the area around Suez Gulf their model overestimated the wind by $\sim 2.5 \mathrm{~ms}^{-1}$.

The discrepancies found in our study, between the model simulations of the current climate and reanalysis data, are in line with findings published in the limited number of previous studies. At this point it should be pointed out that reanalysis data sets also possess some limitations and artifacts (Kistler et al., 2001) and despite their clear utility, there is a need to evaluate the reanalysis projects relative both to other reanalysis data sets and to independent data not assimilated within the reanalysis process (Smith et al., 2001; Schoof and Pryor, 2003). Indeed Pryor et al. (2005) compared mean 10-m wind speeds for the period 1958-2001 as provided by NCEP-NCAR and the ERA40 reanalysis data sets (at $1.875^{\circ} \times 1.875^{\circ}$ and $2.5^{\circ} \times 2.5^{\circ}$ grids respectively). The area of the comparison spans from 53 to $65 \mathrm{~N}$ and from 4 to $26 \mathrm{E}$ (including Nordic countries and the Baltic sea). The authors found the major discrepancies in the two data sets over the areas influenced by the Scandic Mountains where ERA40 mean wind speeds during 1958-2001 were of the order of $1-2.5 \mathrm{~ms}^{-1}$ and NCEP-NCAR winds were of the order of $4-5.5 \mathrm{~ms}^{-1}$. In the same work the authors compared the $10-\mathrm{m}$ winds from the two reanalysis datasets with the climate simulations performed with HadCM3 model (at $2.5 \times 2.5$ grid) for the period 1990-2001. They found the largest discrepancies in terms of the mean wind fields in southern Norway, where, the ERA40 reanalysis indicates mean wind speeds below $2.5 \mathrm{~ms}^{-1}$ and both HadCM3 and the NCEP-NCAR reanalysis data show values in excess of $2.5 \mathrm{~ms}^{-1}$ (namely HadCM3 reproduced winds of $2.5-4 \mathrm{~ms}^{-1}$ and NCEP-NCAR 4-5.5 $\mathrm{ms}^{-1}$ ).

Inspection of the 90th percentile of wind speeds by both ERA40 and PRECIS (Fig. 2b and c) as well as of their differences (Fig. 2d) shows a uniform overestimation by PRECIS that reaches 2-4 ms ${ }^{-1}$ over land surfaces of southern Europe and Turkey and ranges from 0 to $2 \mathrm{~ms}^{-1}$ over the sea. Consequently these differences in wind speed are reflected as a positive bias in energy density over the whole domain in the range of $0-75 \mathrm{Wm}^{-2}$ with the largest differences over the coastal areas of southern Europe (e.g., Corsica, Sardinia, the northern Tyrrhenian Sea and the Aegean Sea), since the higher resolution incorporated in PRECIS permits a better description of the wind flow over these areas.

Figure 3 shows the comparison of the wind field between the future (A2 emission scenario) and the current climate PRECIS model simulations. Individual land grid-cells are denoted as black points in each diagram. The mean difference between A2 and the current climate (Fig. 3a) exhibits a general positive mean difference over land and a negative mean difference over the Mediterranean Sea with the exception of the Aegean Sea region which shows a positive difference. Figure $3 \mathrm{~b}-\mathrm{d}$ shows the 90th percentile wind speeds of the current climate simulation, of the A2 scenario, as well as of their difference. Here it is evident that the increase of wind speeds in the A2 scenario over land and over the Aegean Sea is also reflected in an increase of the highest $10 \%$ winds in the same areas, while respectively the maritime areas exhibit a decrease in their highest $10 \%$ winds. Note the decrease of the highest $10 \%$ of the winds over the sea that occurs in the Eastern Mediterranean and namely in the area of Cyprus. The aforementioned results are in agreement with previous studies. Indeed in the work by Räisänen et al. (2004) who have conducted RCM experiments with two different driving models have shown that for the A2 scenario and for the HadAM3H-driven regional simulations, winds are projected to increase in the future climate by $4 \%$ in a large area over the Balkans and by 4-8\% over the Aegean Sea and Turkey, while a decrease of $4-8 \%$ was found over the central Mediterranean area. A disagreement with the findings by Raisanen et al. (2004) exists for the land surfaces of Italy and part of Greece where the authors show a decrease of winds by $4-8 \%$ while in the current paper an increase of wind is projected in the same areas.

Energy density differences exhibit the same behavior with the mean wind speed differences (Fig. 3e). More specifically, energy density increases by $20 \mathrm{Wm}^{-2}$ over the land surfaces of southern Europe and Turkey and part of northeastern African countries (Tunisia and Libya), while it decreases over the rest of land surfaces with much sharper reductions (of the order of $30-40 \mathrm{Wm}^{-2}$ ) over the maritime areas of eastern Mediterranean, except over the Aegean Sea.

In order to be able to comment on the spatiotemporal variability of the changes of the wind field in the future climate, a closer look to the monthly difference between the PRECIS A2 projection and the current climate simulation is needed.

Figure 4 shows the monthly mean wind speed percent differences between $\mathrm{A} 2$ and current climate simulations. The monthly 2071-2100 to 1961-1990 comparison shows a strong seasonality in the mean wind speed percent difference. Over land, during February and from April through August a significant positive bias is evident (except over northern Africa in July) that reaches $15 \%$ over extended areas, while during December and January wind speeds appear to decrease. This last feature is in agreement with the study by 

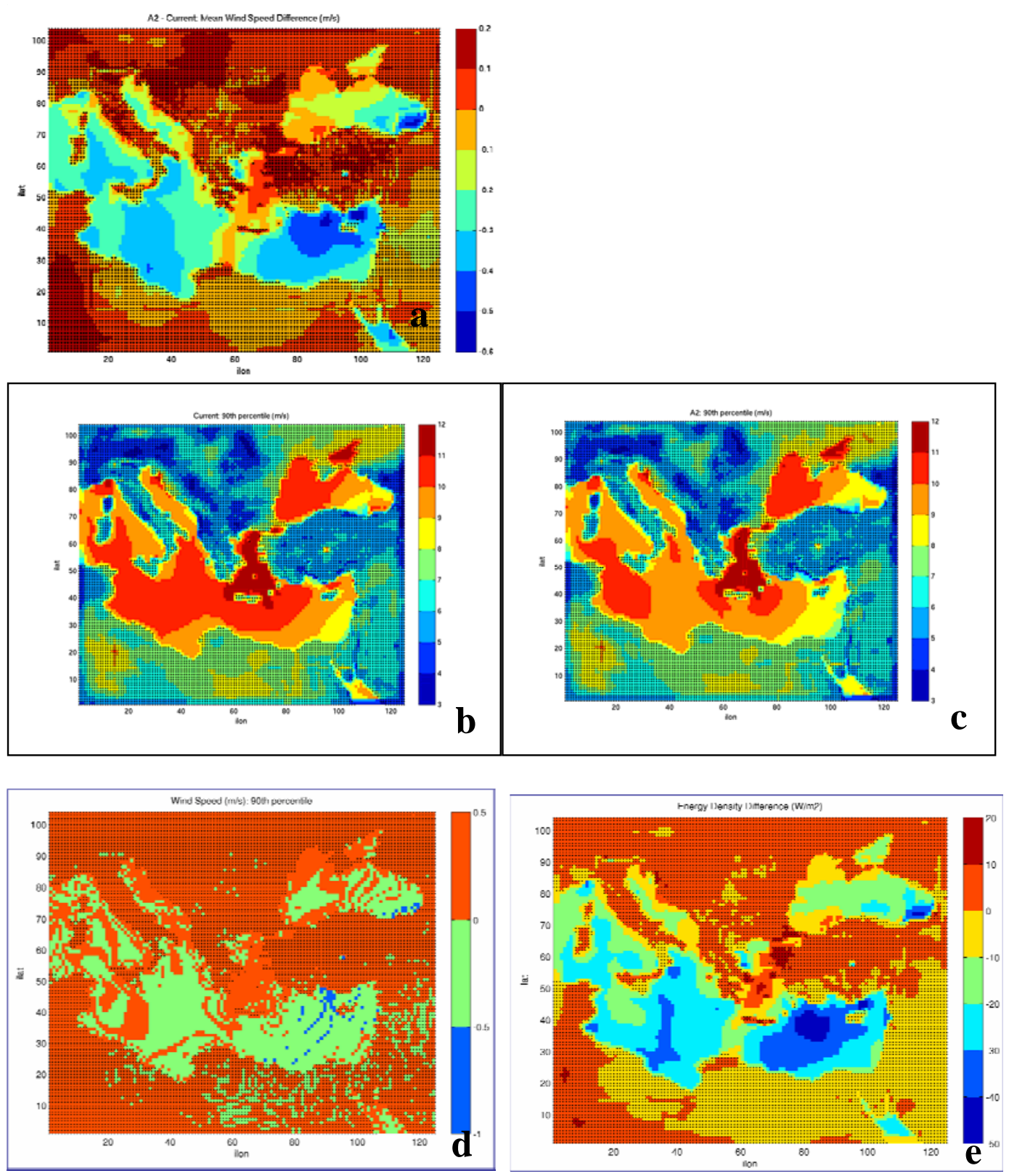

Fig. 3. Comparison between PRECIS A2 climate projection (2071-2100) and current climate simulation (1961-1990): (a) mean wind speed difference, (b) 90th percentile wind speeds for the period 1961-1990, (c), 90th percentile wind speeds for the period 2071-2100, (d) A2-current 90th percentile wind speed difference and (e) A2-current energy density difference.

Rockel and Woth (2007), who also found a decrease of wind speed over the land surfaces in the Mediterranean based on an ensemble of RCM simulations, for the same period. Seasonality changes over the Mediterranean Sea show a high spatial variability: the variability can be categorized into the four general areas of the Tyrrhenian Sea, the Ionian Sea, the Aegean Sea and the Easternmost Mediterranean: this spatial variability appears to a lesser degree in the overall mean wind speed comparison (Fig. 3a). During December, January and May increased negative bias is evident over all four maritime areas that is at least in the range $-5 \%$ to $-10 \%$ and especially in the eastern part of the domain ranges from $-10 \%$ to $-15 \%$.

Lionello et al. (2008), who studied future changes in cyclone climatology over Europe with the use of regional climate simulations, found that following the A2 scenario the cyclonic activity over southern and eastern Europe is projected to attenuate during the winter period. This finding could partly explain the decrease of winds over the Mediterranean during December and January. The eastern-most 

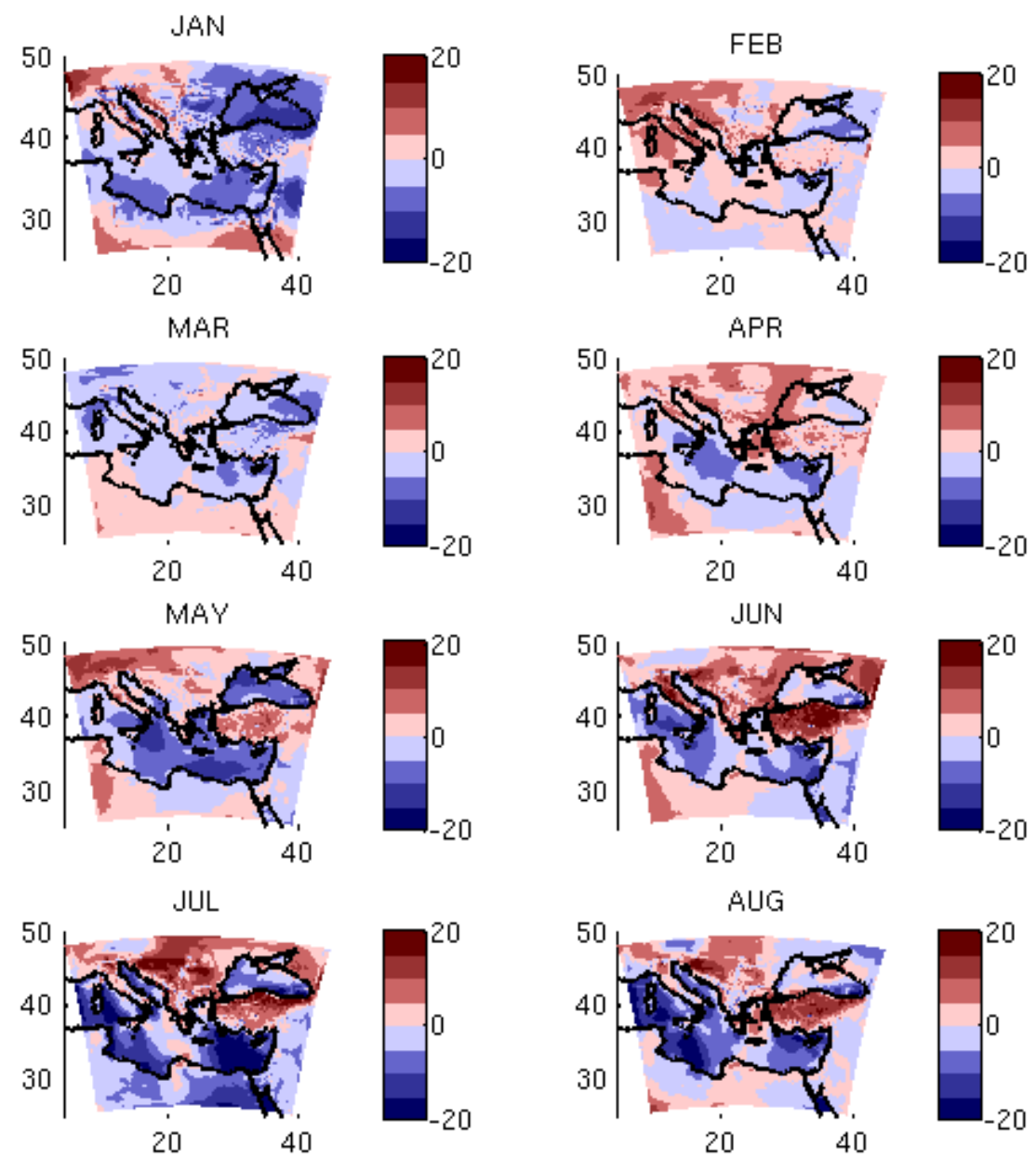

AUG
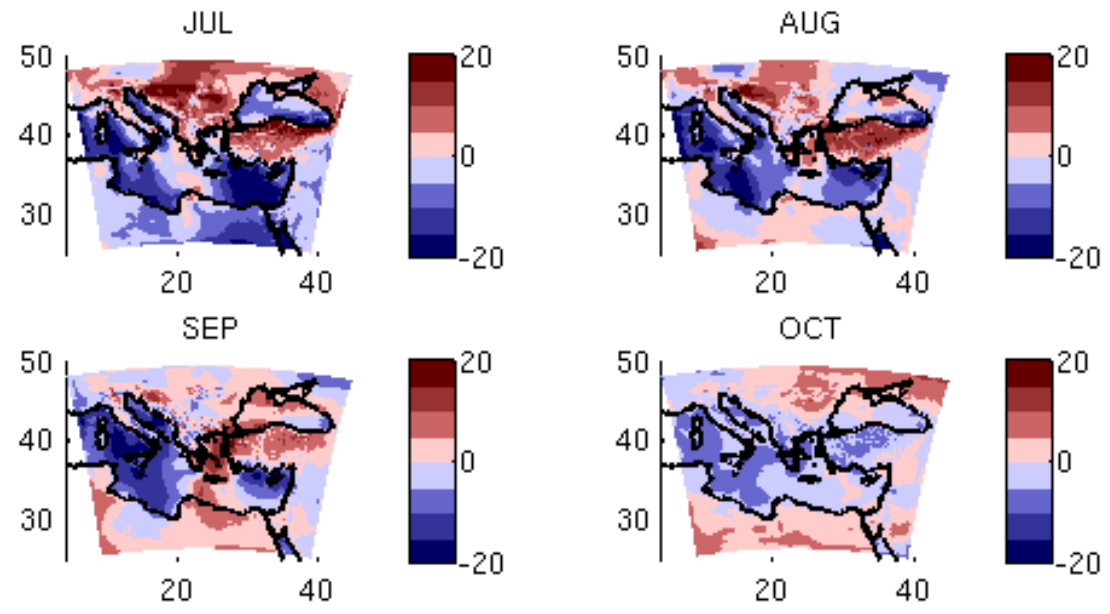

NOV
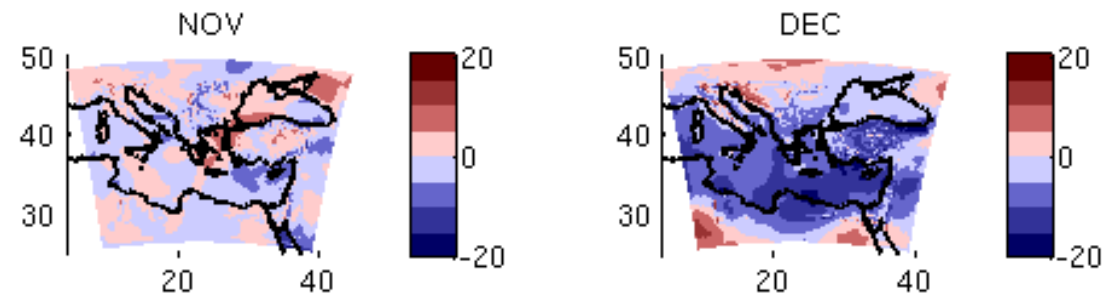

Fig. 4. Monthly mean wind speed percent difference between the A2 projection and the current climate simulation.

part of the Mediterranean exhibits a negative bias during the whole year with the largest negative bias during December, January and May through September. Over the Aegean Sea, a positive bias is found in April (5-10\%), August (5-10\%) and September $(10-15 \%)$. An increase of wind speed by $10 \%$ is quite important on wind energy availability terms as this increase would imply $30 \%$ increase on wind energy. In the study by Krichak et al. (2007) the authors evaluate 
Current climate SEP

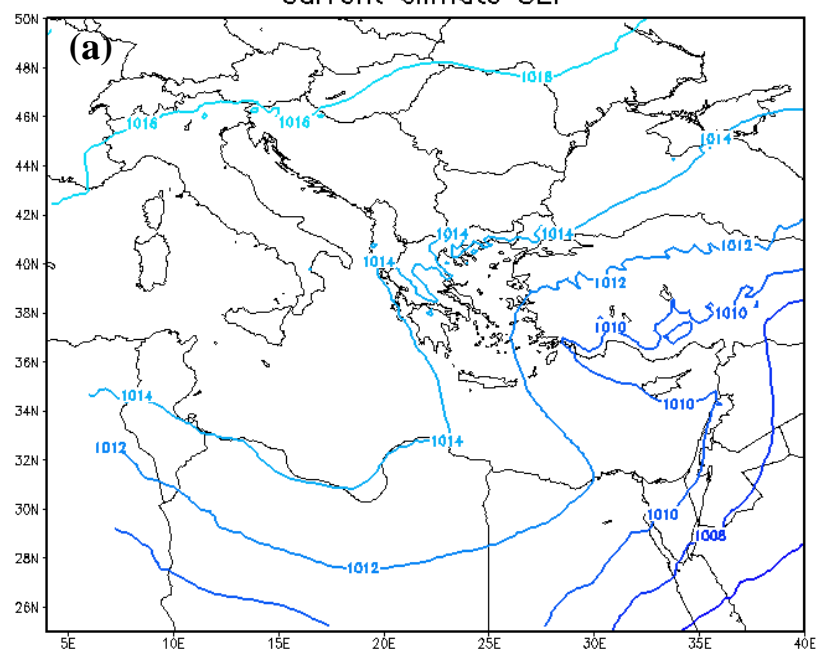

A2 climate SEP

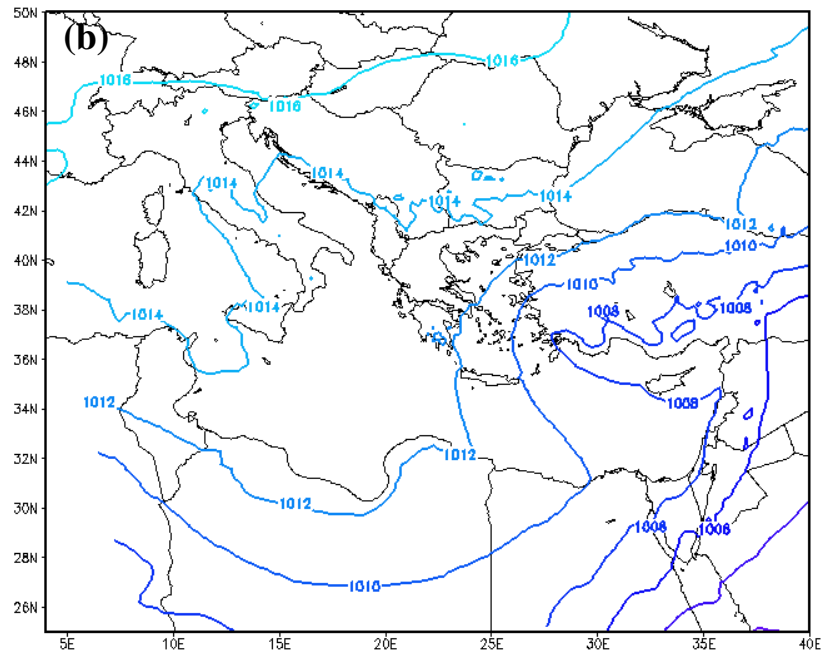

Fig. 5. Average sea-level pressure of September from (a) the current and (b) the future climate simulations.

the expected changes of climate parameters obtained in a three-member ensemble climate change simulation experiment over an area that coincides with the southeastern part of the PRECIS domain presented in this work. As it concerns the wind field, the authors found a decrease of the wind intensity (by $1 \mathrm{~ms}^{-1}$ ) during winter (December to February) over the maritime area of the easternmost part of the Mediterranean which is qualitatively in good agreement with our finding of increased negative bias in the same area of about $-10 \%$ to $-15 \%$ during December and January. Further the authors also found a weakening by $1 \mathrm{~ms}^{-1}$ of the flow over the maritime area of the easternmost part of the Mediterranean and over the area of the Gulf of Suez during summer that is also in qualitative agreement with the results shown in our Fig. 4.
It is worth outlining the occurrence of the Etesian winds which solely take place the Aegean Sea during the summer season. The relatively dry and cool air masses regularly originate from the region of southern Russia and the Black Sea contributing to the decrease of surface temperature and the moderation of summer heat and discomfort (Weather in the Mediterranean, 1962; Metaxas and Bartzokas, 1994; Kotroni et al., 2001). The Etesian winds result from a combination of the monsoon effect that leads to the formation of a thermal low pressure trough over Turkey, with higher pressures over Southern Balkans (Weather in the Mediterranean, 1962; Prezerakos, 1984). In the current climate the maximum frequency of Etesian winds occurs during July and $\mathrm{Au}-$ gust (Prezerakos, 1984). The increase of the winds in the future climate during September could be related to the extension of the period of prevalence of the thermal low over Turkey up to September leading to the occurrence of Etesian winds also during this month. Figure 5 shows the average sea-level pressure of September from the current and the future climate simulations. In both figures the surface low pressure trough over southern Turkey and Middle East is evident but during the future climate the surface low is by $2 \mathrm{hPa}$ deeper and the pressure gradient over the Aegean Sea is sharper.

In order to determine the intensity of the Etesian winds in terms of the pressure gradient over the Aegean, forecasters in the Hellenic Meteorological Service (Ziakopoulos, personal communication) calculate the pressure difference between Athens and Rhodes island (for locations see Fig. 1). For that reason and with the aim to investigate the relation of the increase of winds in the future climate during summer and up to September with the prevailing synoptic conditions, the daily differences of pressure between Athens and Rhodes have been calculated from June through September from both the current and the future climate simulations. The pressure differences have been divided to bins of $2 \mathrm{hPa}$ and the relative frequencies within the 30 year periods of the current and the future climate have been calculated for each month. Figure 6 shows the relative frequencies of the various bins of pressure difference for July and September. During July (Fig. 6a) and for bins greater than $4 \mathrm{hPa}$ the relative frequencies between the current and the future climate do not change significantly. On the other hand during September (Fig. 6b) the relative frequencies of occurrence of pressure differences larger than $4 \mathrm{hPa}$ are increasing during the future climate, explaining the increased mean winds over the Aegean.

An increase in wind and the wind energy availability during the summer period over the Aegean could be considered beneficial as there is an increased energy demand due to the increased tourism activity in the region. Over the Ionian Sea the negative bias is more pronounced during April, May, August, September and December. Over the Tyrrhenian Sea there is a positive bias in February and a pronounced negative bias from June through September and December. 

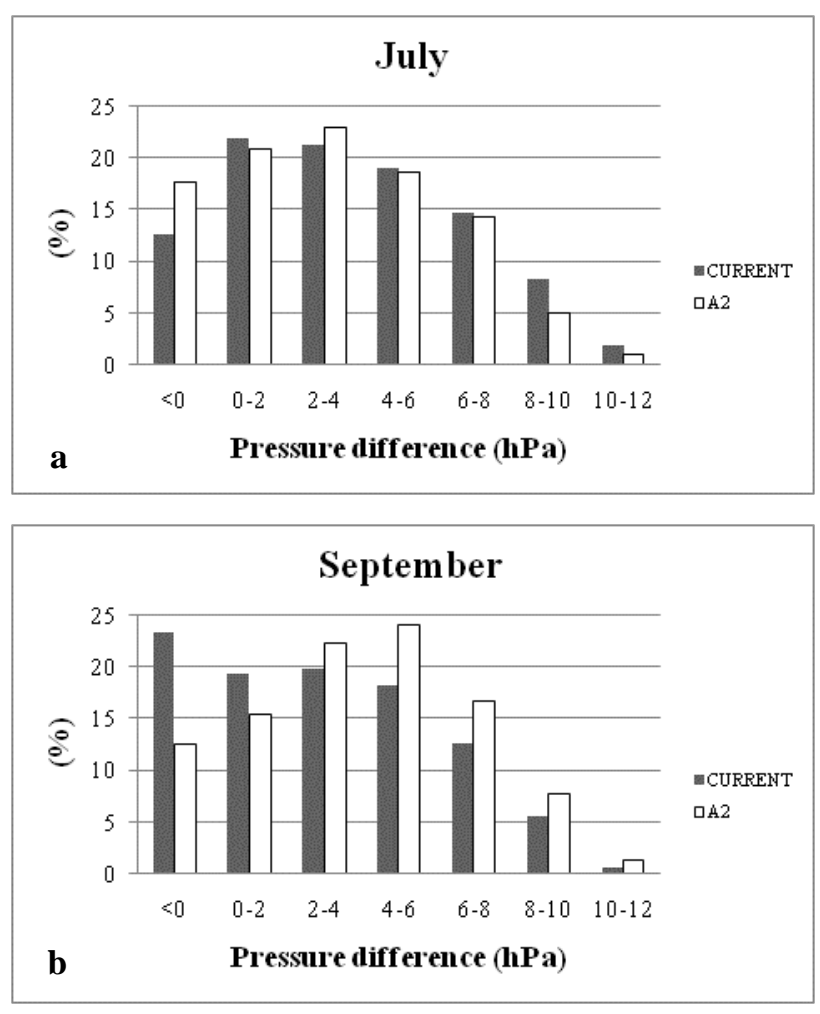

Fig. 6. Relative frequencies of various bins of pressure difference over the Aegean sea for (a) July and (b) September derived from the 30 year integrations of the current (white bars) and the future (black bars) climate.

\section{Summary and concluding remarks}

The main objective of this paper is to assess the possible future change of the wind speed and of the resulting wind energy availability up to the end of the 21 st century. The analysis is based on the simulated wind field of the current climate (1961-1990) and of the projection based on IPCC A2 scenario for the period (2071-2100). The simulations were performed with the regional climate model PRECIS. The originality of the study relies on the analysis of relatively high resolution climate simulations $(\sim 22 \mathrm{~km} \times 22 \mathrm{~km})$ that is considered necessary in order to study climate change impacts in the Eastern Mediterranean which is characterised by complex topography and land-water distribution.

The comparison between the PRECIS current climate simulations of the wind speed and the ERA40 re-analysis wind speed exhibits smaller differences over land than over the sea, with mean absolute differences varying from 1 to $2.5 \mathrm{~ms}^{-1}$ and from 2.5 to $4.5 \mathrm{~ms}^{-1}$ respectively. These differences were attributed to the different spatial resolution of ERA40 $\left(1^{\circ} \times 1^{\circ}\right)$ and of PRECIS model $\left(0.22^{\circ} \times 0.22^{\circ}\right)$ and thus in the degree of specificality of the underlying terrain that induces differences in the drag and the blocking by the mountains.

Comparison of the current and future climate simulations shows an increase in mean wind speeds over land and a decrease over the Mediterranean Sea with the exception of the Aegean Sea. There is an overall wind energy density decrease over the model sea cells, with the exception of an increase over the Aegean Sea. The analysis of monthly data shows that the differences in wind speeds between the current and future climate portray a significant seasonality. Over land, from April through August a significant positive bias is evident while during December and January wind speeds appear to decrease. Over the maritime areas the main characteristics are the projected decrease in wind speeds during December, January and May and a noticeable increase over the Aegean Sea during April, August and September. The increase of the winds in August and mainly in September were found to be related to the deeper surface low pressure trough over Turkey and middle east that enhances the pressure gradient over the Aegean Sea. Further study is required to better understand the effect of the Aegean Sea's small scale heterogeneity on mesoscale models such as PRECIS.

The results show the sharp differences in behavior between subsections of the East Mediterranean and thus outline the need to improve the quantification of changing wind energy availability in the 21 st century. Further research efforts are required to evaluate the possibility of dynamic downscaling to determine the climate induced wind speed changes over the East Mediterranean and the resulting wind energy availability. Closing this section, it should be noted that the results presented in this paper should be treated with care as there are uncertainty factors in all regional climate simulations related among others to the choice of the emission scenario and to the driving global climate model. That is the reason why in large European projects such as PRUDENCE and ENSEMBLES, a systematic choice of regional climate model experiments with a variety of emission scenarios and global models is being performed (Christensen and Christensen, 2007).

Acknowledgements. The authors wish to thank the Hadley Centre for providing the PRECIS code to the National Observatory of Athens and namely R. Jones and R. D. Hassell. Additionally the ECMWF is acknowledged for the provision of the ERA40 data set.

Edited by: A. Mugnai and A. Jansà

Reviewed by: two anonymous referees 


\section{References}

Christensen, J. H. and Christensen, O. B.: A summary of the PRUDENCE model projections of changes in European climate by the end of the century, Clim. Dynam., 16, 147-168, Clim. Dynam., 81, 7-30, 2007.

Farrugia, R. N.: The wind shear exponent in a Mediterranean island climate, Renewable Energy, 28, 647-653, 2003.

Gao, X., Pal, J., and, Giorgi, F.: Projected changes in mean and extreme precipitation over the Mediterranean region from a high resolution double nested RCM simulations, Geophys. Res. Lett., 33, L03706, doi:10.1029/2005GL024954, 2006.

Gordon, C., Cooper, C., Senior, C. A., Banks, H., Gregory, J. M., Johns, T. C., Mitchell, J. F. B., and Wood, R. A.: The simulation of SST, sea ice extents and ocean heat transports in a version of the Hadley Centre coupled model without flux adjustments, Clim. Dynam., 16, 147-168, 2000.

IPCC: Climate change, The scientific basis, The Edinburgh Building Shaftesbury Road, Cambridge, CB2 2RU England, 881 pp., 2001.

Jones, R., Noguer, M., Hassell, D., Hudson, D., Wilson, S, Jenkins G., and Mitchell, J.: Generating high resolution climate change scenarios using PRECIS, Met Office Hadley Centre, Exeter UK, 40 pp., 2004.

Kistler, R., Kalnay, E., Collins, W., Saha, S., White, G., Woollen, J., Chelliah, M., Ebisuzaki, W., Kanamitsu, M., Kousky, V., van den Dool, H., Jenne, R., and Fiorino, M.: The NCEP-NCAR 50 year reanalysis: monthly mean $\mathrm{CD}-\mathrm{ROM}$ and documentation, Bull. Amer. Meteorol. Soc., 82, 247-267, 2001.

Kotroni, V., Lagouvardos, K., and Lalas, D.: The effect of Crete island on the Etesian winds over the Aegean Sea, Q. J. Roy. Meteor. Soc., 127, 1917-1938, 2001.

Kotroni, V., Lykoudis, S., Lagouvardos, K., and Lalas, D.: A fine resolution regional climate change experiment for the Eastern Mediterranean: analysis of the present climate simulations, Global Planet. Change, 64, 93-104, 2008.
Krichak, S. O., Alpert, P., Bassat, K., and Kunin, P.: The surface climatology of the eastern Mediterranean region obtained in a three-member ensemble climate change simulation experiment, Adv. Geosci., 12, 67-80, 2007, http://www.adv-geosci.net/12/67/2007/.

Lionello P., Boldrin, U., and, Giorgi, F.: Future changes in cyclone climatology over Europe as inferred from a regional climate simulation, Clim. Dynam., 30, 657-671, 2008.

Metaxas, D. and Bartzokas, A.: Pressure covariability over the Atlantic, Europe and N. Africa. Application: centers of action for temperature, winter precipitation and summer winds in Athens, Greece, Theor. Appl. Climatol., 49, 9-18, 1994.

Pope, V. D., Gallani, M. L., Rowntree, P. R., and Stratton, R. A.: The impact of new physical parametrizations in the Hadley Centre climate model - HadAM3, Clim. Dynam., 16, 123-146, 2000.

Prezerakos, N. G.: Does the extension of the Azores anticyclone towards the Balkans really exist, Arch. Meteorol. Geophys. Bioklimatol. Ser. A., 33, 217-227, 1984.

Pryor, S. C., Barthelmie, R. J., Kjellstrom, E.: Potential climate change impact on wind energy resources in northern Europe: analyses using a regional climate model, Clim. Dynam., 25, 815835, 2005.

Räisänen, J., Hansson, U., Ullerstig, A., Döscher, R., Graham, L. P., Jones, C., Meier, H. E. M, Samuelsson, P., Willén, U.: European climate in the late twenty-first century: regional simulations with two driving global models and two forcing scenarios, Clim. Dynam., 22, 13-31, 2004.

Rockel, B. and Woth, K.: Extremes of near-surface wind speed over Europe and their future changes as estimated from an ensemble of RCM simulations, Climatic Change, 81, 267-280, 2007.

Weather in the Mediterranean, Meteorological Office, Vol. I, General Meteorology H. M. Stat. Office, London, 2nd Ed., 1962. 